\title{
Introduction of the Biokinemetric Triangle \\ - a New Surrogate Parameter for Analysis of Spinal Range of Motion
}

\author{
Bernhard Rieger, ${ }^{1 *}$, Clemens Reinshagen², Jozef Živč́k ${ }^{3}$, Radovan Hudák , Jürgen Hescheler ${ }^{4}$, \\ Michael Mokry ${ }^{5}$, Marek Molcanyi ${ }^{6}$ \\ 1 Department of Neurosurgery, Carl Gustav Carus University Hospital, Technical University of Dresden, 01307 Dresden, Germany \\ ${ }^{2}$ Department of Radiology, Massachusetts General Hospital, Harvard Medical School, Boston, MA, USA \\ ${ }^{3}$ Department of Biomedical Engineering and Measurement, Technical University of Košice, Letná 9, 04200 Košice, Slovakia \\ ${ }^{4}$ Uniklinik Koln, Institute of Neurophysiology, Germany \\ ${ }^{5}$ Department of Neurosurgery, Auenbruggerplatz 29, 8036 Graz, Austria \\ ${ }^{6}$ Institute of Neurophysiology, Medical Faculty, University of Cologne, 50937 Cologne, Germany
}

\begin{abstract}
Background: In preparation for a cervical device study (CDS) we developed a software-based surrogate model in order to analyze pre- and postoperative segmental range-of-motion (ROM) and help determine the optimal height of cervical implants. Besides eliminating surgeon's bias during intraoperative device-height choice, this software-based approach to spinal implantation surgery aims to reduce postoperative neck pain. In this study we evaluated the feasibility of using this surrogate model to determine changes in pre- and postoperative segmental motion characteristics independent of surgeonrelated bias of device-height choice. Methods: The software's surrogate model is based on videofluoroscopic movement recordings in addition to conventional radiographs recorded during standardized movements. Software-based evaluation of segment-specific rangeof-motion (ROM) characteristics was based on the newly introduced surrogate parameter "biokinemetric triangle". Depending on changes of the triangles surface area during preand post-operative analysis, segment-specific ROM were determined and evaluated with regards to surgery-related ROM changes. Structural pattern recognition was employed to examine whether biokinemetric triangle based ROM analysis is able to discriminate between different implants. Results: The surrogate parameter biokinemetric triangle software plug-in allows detection of implant-specific functional alterations of segmental movement characteristics $(p<0.05)$. It is a valuable follow-up parameter for the investigation of changes in the segmental motion characteristics after device implantation. Conclusions: Biokinemetric triangle analysis displays segmental motion characteristics and detects segmental changes after device implantation in CDS. Common range of motion (ROM) analysis based on angular observations requires complete movement execution in order to make significant comparisons, whereas the triangle-based analysis allows movement characterization independent of complete execution.
\end{abstract}

Keywords: cervical discectomy, cervical prosthesis, cervical cage, biokinemetric triangle, segmental range of motion

\section{Introduction}

Recently, the German Patent and Trademark Office (DPMA) has disclosed "Biokinemetrie" as a procedural method for creating improved prosthetics in spinal degeneration by the example of a medial interspinous device, designed to support 
the facet joints $[23,27]$. Biokinemetrie defines the mathematical decryption of physiologic segmental movement, which may allow functional replacement of a vertebral motion-segment with a prosthetic device $[7,30,32,33,34]$. One possible use for the functional replacement of a spinal segment could be the desire to avoid iatrogenic adjacent level disease after stabilizing surgery. However, whether iatrogenic adjacent level disease really exists is currently still debated [26]. In order to find the answer to this question we recently started a cervical device study (CDS), which consists of two parts (PNS study NCT02936765 and PNR study NCT02936739) [24]. In the PNS study, mono-segmental cervical discectomy is followed by either implantation of an Elastic Spine PAD ${ }^{\mathrm{TM}}$ (FH Orthopedics ${ }^{\oplus}$, France) or the implantation of a polyetherketoneketone (PEKK) cage (Squale $^{\text {TM }}$ manufactured by OSD $^{\circledR}$ orthopaedic \& spine development, France). In the PNR study, monosegmental cervical discectomy is followed by either implantation of an Elastic Spine PAD ${ }^{\text {TM }}$ or implantation of a cervical prosthesis (Rotaio $^{\text {TM }}$ manufactured by Signus ${ }^{\oplus}$, Germany). The three devices used in the two studies are technically different. The PEKK cage is expected to induce rigid bony fusion, the Elastic Spine PAD ${ }^{\mathrm{TM}}$ can be considered as an elastic cage resulting in dynamic rigidity of the implanted segment, and the Rotaio ${ }^{\mathrm{TM}}$ prosthesis is based on a slipping hinge joint and may therefore preserve segmental movement in a mechanically pre-defined manner. The underlying hypothesis of the study is: if the segments adjacent to the implanted devices degenerate significantly different during follow-up this would be due to device-specific differences [29]. Primary clinical endpoint of the studies is the Neck Disability Index. However, since postoperative neck pain is significantly influenced by implant-height [15], we aimed to eliminate this bias via preoperative software-based objective determination of the optimal device height for each patient. Therefore, the simulation software introduced in the current study was designed to propose the height of the implant and takes into consideration the current state of degeneration in order to avoid device-induced overcorrection $[3,4,6,9,28,31]$. The algorithm of the software is hereby based on the assessment of predefined standardized spinal videofluoroscopic movement recordings, which were interpreted as cinematographic investigations $[1,2,13,16,19]$. During assessment of patients, the software can then combine these predefined datasets with data acquired from standard movement radiographs (extension, neutral and flexion) in order to approximate patient-specific segmental ROM and suggest the implants optimal height. Postoperatively the same software-based evaluation is used for follow-up evaluation of surgery-related changes of segmental ROM, thereby also allowing continuous improvement of the software's algorithm with the ultimate goal to improve patient outcome.

\section{Method}

To describe the functional alteration of adjacent levels after implantation of a specific device the surrogate parameter "biokinemetric triangle" was integrated into the software. This element has already been shortly mentioned in a previous proceeding [26]. Hereby, the triangle's baseline is defined by the lower vertebra's upper plate and reaches from the leading edge of the lower vertebra ( $1^{\text {st }}$ point) to the ascending lateral facet ( $2^{\text {nd }}$ point). The $3 r d$ point is defined by the rear edge of the upper vertebra at the roof of the neuroforamen (Fig. 1). Because its baseline is fixed, the triangle only changes its height during movement. The change of the triangles' height defines the movement of the 3rd point at the roof of the neuroforamen with respect to the underlying vertebra, thus characterizing the segmental movement pattern. The characteristic curves displayed in the diagram (Fig. 2) result from the change of the triangles' surfaces area (Fig. 3) during the spine's movement (Fig. 4) and indicate (from left to right) changes in segmental motion from extension (left) to flexion (right). To further define inter-segmental communicating movement patterns, the algorithm additionally calculates the ratio between $\Delta S$ and the percentile segmental position within the total movementsequence $(\Delta S / \Delta \%)$. The software determines the triangles surface every $2.5 \%$ of the full movementsequence, thus movement characteristics of each segment are represented by three real (extension, neutral and flexion) and thirty-eight virtually calculated measurements.

Software-based cervical movement measurements are performed in all patients of the CDS pre- 


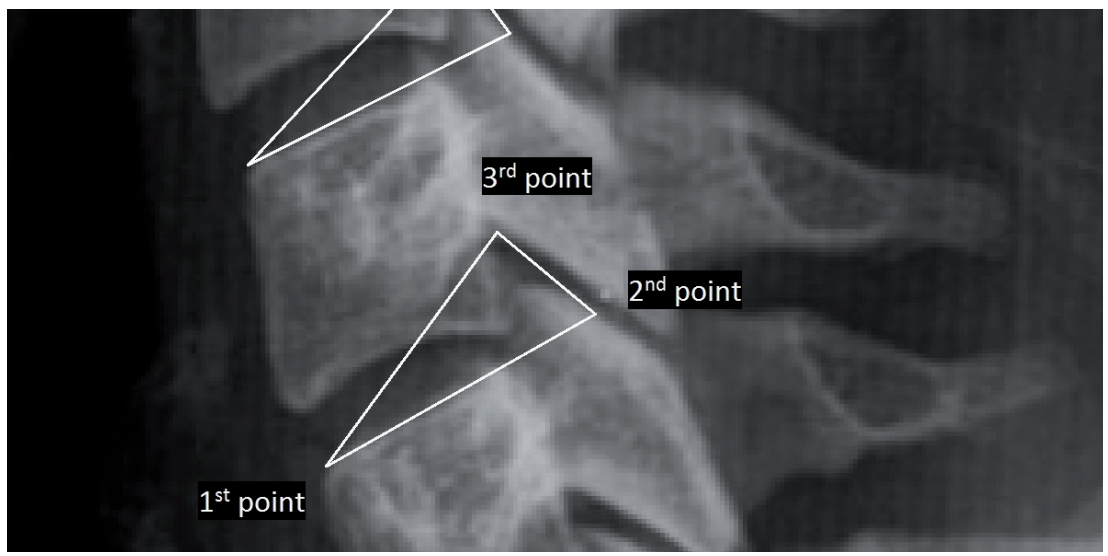

Fig. 1: Definition of the triangle configuration for biokinemetric characterization of the segment.

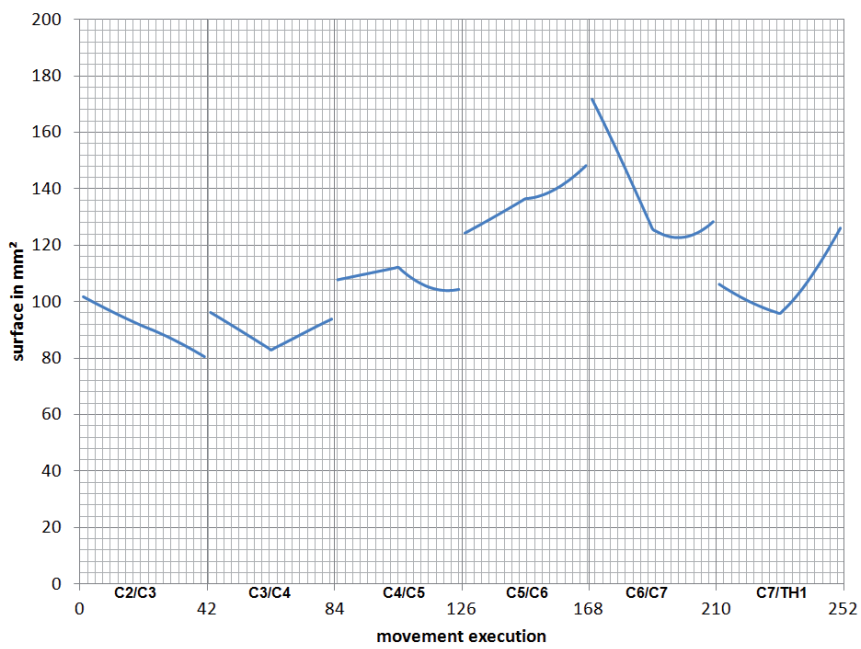

Fig. 2: Movement characteristics of the different levels expressed via change of the triangle's surface.

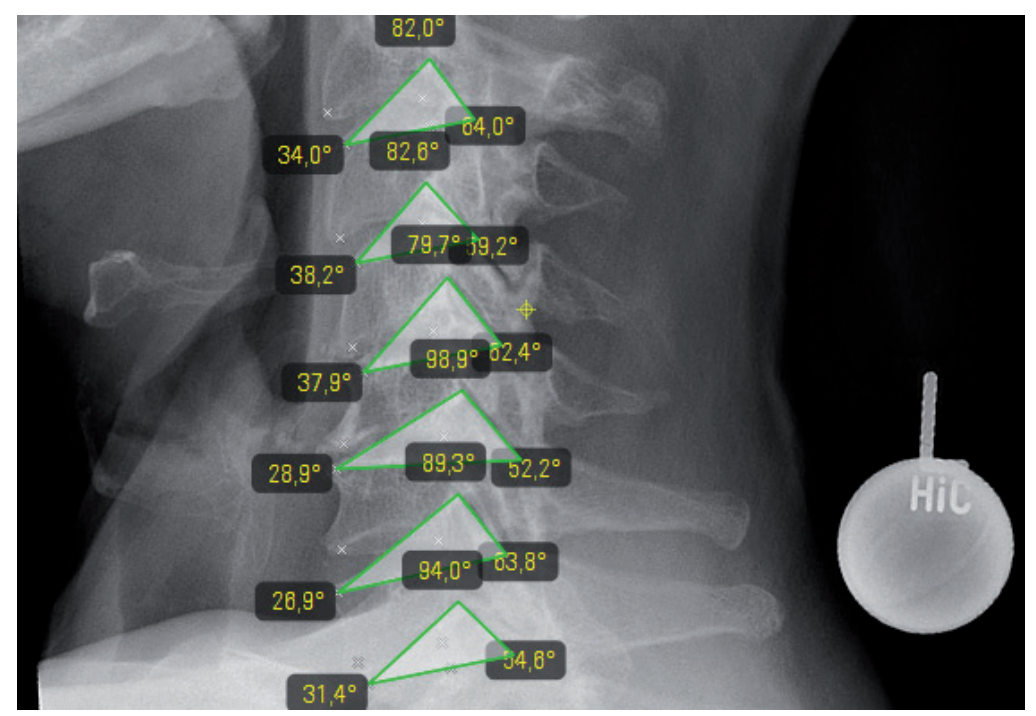

Fig. 3: Segmental projection of the triangles which generate the curves in Fig. 2 due to the change of their surface area during the movement. Preoperative values of respective triangles, before implantation of SqualeTM in C5/C6. 


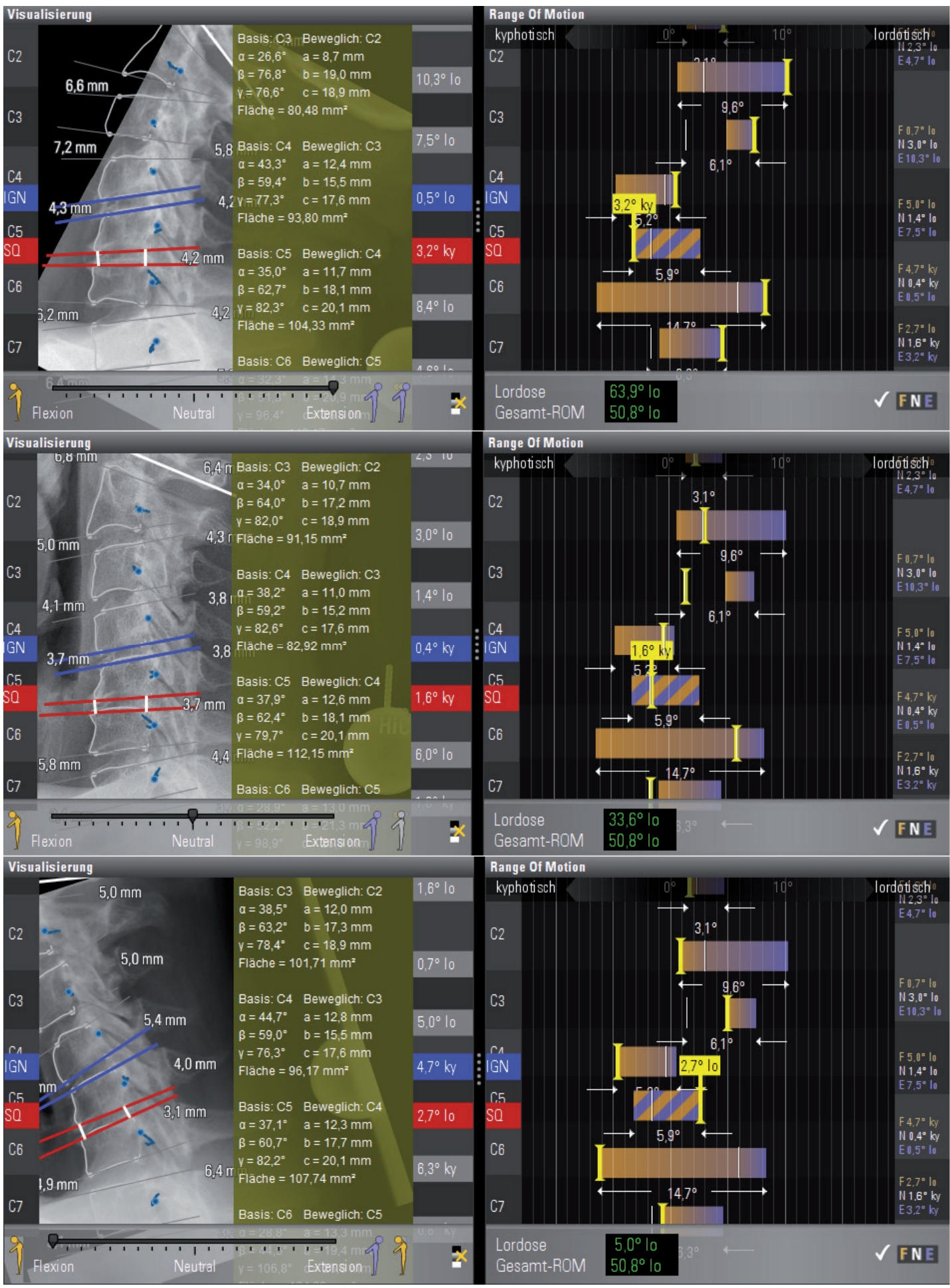

Fig. 4: Preoperative movement-simulation of the considered spine with common range of motion analysis. 
operatively and will be acquired at three-month, at six-month and at one year following surgery, thereby assessing in detail the inter-segmental communication after device implantation. Structural pattern recognition is used to investigate whether the biokinemetric triangle analysis is able to discriminate between different implants with regards to patient-specific changes in adjacent segmental motion.

The decisive advantage of the biokinemetric triangle is that motion characteristics can be compared with each other at different examination times even when the motion is not performed in full completion $[24,25]$.

\section{Results}

A Software-based evaluation of cervical anatomy and movement-patterns helped the surgeon to preoperatively determine the implants device height. Preliminary follow-up via the software's biokinemetric triangle plugin additionally demonstrated significant changes in postoperative segmental movement characteristics $(p<0.05)$. Moreover, the recorded postoperative data demonstrates devicespecific changes of adjacent level ROM, which propagated over several adjacent levels (Fig. 5 in comparison with Fig. 2). The biokinemetric triangle was validated as an appropriate surrogate parameter for monitoring the change of segmental functionality in the follow-up of CDS patients (Fig. 6, 7).
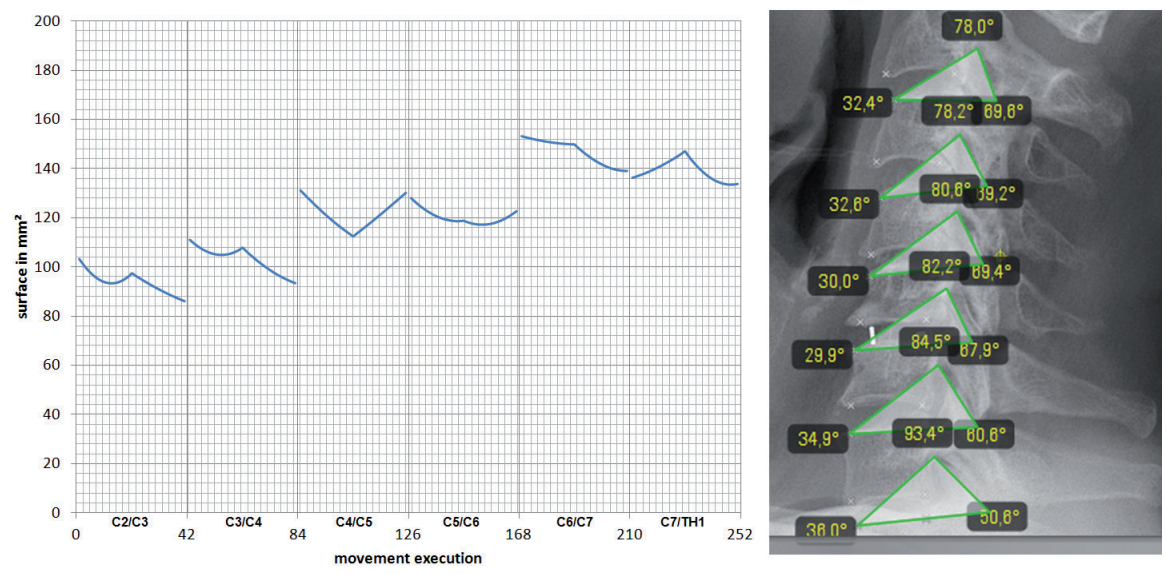

Fig. 5: 3-month follow-up after implantation of Squale $e^{T M}$ in C5/C6.

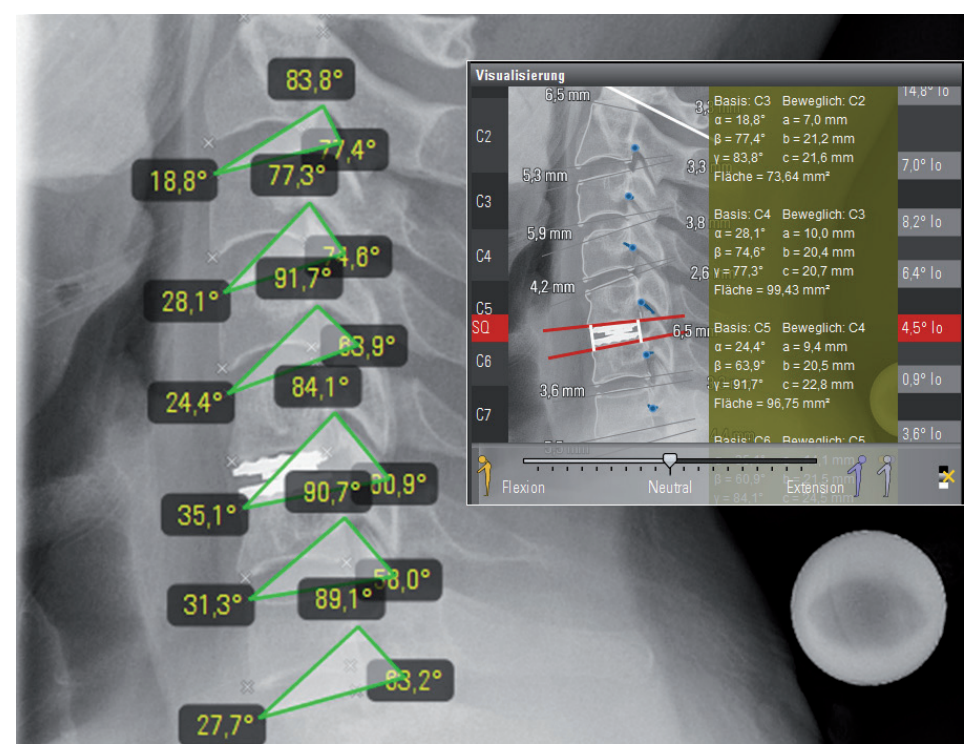

Fig. 6: 3 month follow-up after implantation of Rotaio ${ }^{T M}$. 

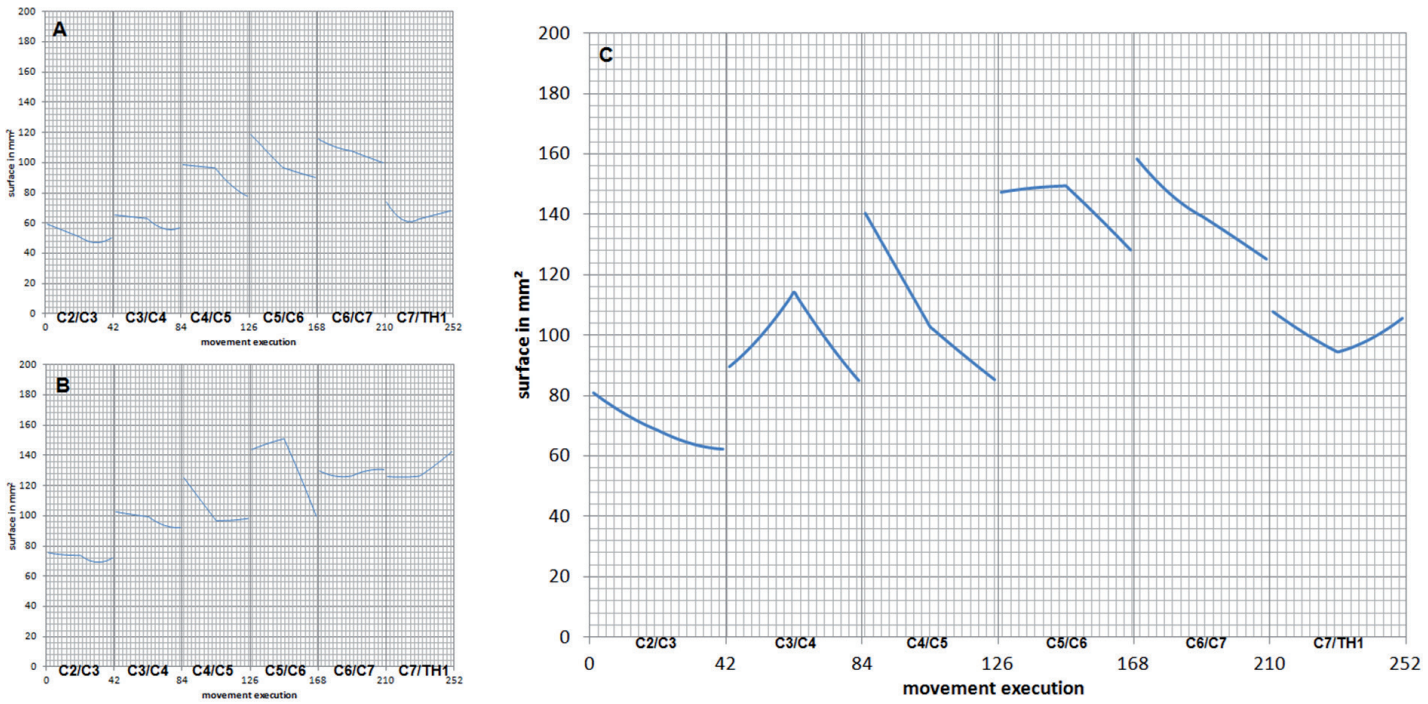

Fig. 7: Before implantation of Rotaio ${ }^{T M}$ in C5/C6. B: 3-month follow-up after implantation of Rotaio ${ }^{\text {TM }}$ in C5/C6. C: 6-month follow-up. The triangle's consideration is able to identify the implanted device via pattern recognition based on the displayed changing motion characteristics. In the case of the Rotaio ${ }^{T M}$ prosthesis, this alteration is particularly pronounced (B). Therefore, in the further course (C), there is a physiological restriction of the non-physiological movement and consequent increasing stress in the adjacent segments.

\section{Discussion}

In this study we introduce the biokinemetric triangle and demonstrate several representative examples of a software-based approach to assess cervical anatomy and segmental motion patterns, helping surgeons during preoperative device choice and postoperative functional follow-up. We outline the fact that cervical device implantation leads to significant changes in postoperative movement characteristics not only in the operated, but also in adjacent segments and further found that changes propagated over several adjacent levels. Patientspecific segmental degeneration may require patient-tailored device choices, with the intent to restore segmental movement patterns as close as possible to physiological ROM and prevent longterm disability. The ability to integrate softwarebased ROM-analysis into the surgical preparation and follow-up therefore presents a valuable opportunity to help surgeons as well as device-manufacturers to objectively optimize device-choice and -properties according to patient-specific needs.

The human spine is a complex structure of mechanically-linked segments, in which segmentspecific ROM is determined by compositemovement patterns thereby differing from most other joints of the body. Software-based analysis using the biokinemetric triangle is able to display movement characteristics without confusing angle considerations and aims to describe segmental movement by focusing analysis on a single point at the roof of the neuroforamen (3rd point, height of triangle) [25]. The bony real analog of this point of interest moves around the nerve root in a specific manner, which could be described as a slipping or translational movement due to it's instantaneous center of rotation [30]. Physiologically, this movement-pattern prevents nerve-root impingement at the neuroforamen. In comparison to common ROM analysis, which is based on angular observations, the biokinemetric triangle based observation does not require complete movement execution. In the CDS the biokinemetric triangle plugin is currently used to characterize cervical movement based on sagittal imaging data only. However, in order to further extent accuracy during movement analysis and device-specific prediction of postoperative ROM changes, it will likely be beneficial to further integrate the anterior-posterior (a-p) plane into the biokinemetric analysis [26]. Therefore our current software development aims to transition from 2D plane radiographic analysis to 3D computed tomography based data acquisition [22]. 


\section{Conclusion}

The aim of the introduction of the biokinemetric triangle is to mathematically approximate the movement patterns of the spine in order to facilitate an improved spinal prosthetic restoration [23]. Even though our preliminary CDS data demonstrates that there are device-specific changes in postoperative segmental and adjacent level ROM, it is currently too early to determine whether these variations will translate into significantly different radiological and clinical courses of degeneration. Long-term patient follow-up will help to further improve the software's algorithm and determine it's predictive value regarding patient-outcome.

\section{Acknowledgments}

We thank the company Spontech Medical AG (Stuttgart) for supplying the software Vertaplan, utilized in this study. We also thank Sebastian Zachar M.F.A. for his long-term cooperation and support during preparation and formatting of the figures. The cooperative networking between first author and Technical University of Kosice was in part supported by the Slovak Research and Development Agency under the contract No. APVV-15-0356 and No. APVV-14-0294.

\section{References and Notes}

[1] Anderst WJ, Aucie Y. Three-dimensional intervertebral range of motion in the cervical spine: Does the method of calculation matter? Med Eng Phys 2017 41:109-15.

[2] Anderst WJ, Donaldson 3rd. WF, Lee JY, Kang JD. Three-dimensional intervertebral kinematics in the healthy young adult cervical spine during dynamic functional loading. J Biomech. 2015 48(7) 1286-93.

[3] Berthonnaud E, Labelle H, Roussouly P, Grimard G, Vaz G, Dimnet J. A variability study of computerized sagittal spinopelvic radiologic measurements of trunk balance. J Spinal Disord Tech 2005 18(1):66-71.

[4] Berthonnaud E, Dimnet J, Roussouly P, Labelle H. Analysis of the sagittal balance of the spine and pelvis using shape and orientation parameters. J Spinal Disord Tech 2005 18(1):407.

[5] Bossert M. Einführung in die Nachrichtentechnik. 2012 Oldenbourg Wissenschaftsverlag.

[6] Boulay C, Tardieu C, Hecquet J, Benaim C, Mouilleseaux B, Marty C, Prat-Pradal D, Legaye J, Duval-Beaupère G, Pélissier J. Sagittal alignment of spine and pelvis regulated by pelvic incidence: standard values and prediction of lordosis. Eur Spine J 2006 15(4):415-22.

[7] Daniels Ah, Paller DJ, Koruprolu S, Palumbo MA, Crisco JJ. Dynamic biomechanical examination of the lumbar spine with implanted total spinal segment replacement (TSSR) utilizing a pendulum testing system. PLoS One 2013 8(2).

[8] Diebo BG, Ferrero E, Lafage R, Challier V, Liabaud B, Liu S, Vital JM, Errico TJ, Schwab FJ, Lafage V. Recruitment of compensatory mechanisms in sagittal spinal malalignment is age and regional deformity dependent: a full-standing axis analysis of key radiographical parameters. Spine 2015 40(9):642-9.

[9] Ferrero E, Liabaud B, Challier V, Lafage R, Diebo BG, Vira S, Liu S, Vital JM, Ilharreborde B, Protopsaltis TS, Errico TJ, Schwab FJ, Lafage $\mathrm{V}$. Role of pelvic translation and lower-extremity compensation to maintain gravity line position in spinal deformity. J Neurosurg Spine 2016 24(3):436-46.

[10] Gertzbein SD, Seligman J, Holtby R, Chan KH, Kapasouri A, Tile M, Cruickshank B. Centrode patterns and segmental instability in degenerative disc disease. Spine 1985 10(3):25761.

[11] Gertzbein SD, Chan KH, Tile M, Seligman J, Kapasouri A. Moiré patterns: an accurate technique for determination of the locus of the centres of rotation. J Biomech. 1985 18(7):5019.

[12] Gertzbein SD, Holtby R, Tile M, Kapasouri A, Chan KW, Cruickshank B. Determination of a locus of instantaneous centers of rotation of the lumbar disc by moiré fringes. A new technique.

[13] Guigui P, Levassor N, Rillardon L, Wodecki P, Cardinne L. Physiological value of pelvic and spinal parameters of sagittal balance: analysis of 250 healthy volunteers. Rev Chir Orthop Reparatrice Appar Mot 2003 89(6):496-506.

[14] Gutman G, Labelle H, Barchi S, Roussouly P, Berthonnaud É, Mac-Thiong JM. Normal sagittal parameters of global spinal balance in children and adolescents: a prospective study of 646 asymptomatic subjects. Eur Spine J 2016 25(11):3650-7.

[15] Kwon B, Kim D, Marvin A, Jenis LG. Outcomes following anterior cervical discectomy and fusion: The role of interbody disc height, angulation and spinous process distance. J Spinal Disord Tech 2005 18:304-308.

[16] Lafage R, Ferrero E, Henry JK, Challier V, Diebo B, Liabaud B, Lafage $V$, Schwab F. Validation of a new computer-assisted tool to measure spino-pelvic parameters. Spine J 2015 15(12):2493-502.

[17] Legaye J, Duval-Beaupère G. Sagittal plane alignment of the spine and gravity: a radiological and clinical evaluation. Acta Orthop Belg 2005 71(2):213-20.

[18] Niederer D, Vogt L, Wilke J, Banzer W. On the relevance of surrogate parameter deduction in biomedical research: mediated regression analysis for variance explantation of cervical range of motion. Eur Spine J 2017 26(1):162-166.

[19] Okawa A, Shinomiya K, Komori H, Muneta T, Arai Y, Nakai O. Dynamic motion study of the whole lumbar spine by video- 
fluoroscopy. Spine 1998 23(16):1743-49.

[20] Pearcy MJ, Bogduk N. Instantaneous axes of rotation of the lumbar intervertebral joints. Spine 1988 13(9):1033-41.

[21] Pearcy MJ, Whittle MW. Movements of the lumbar spine measured by three-dimensional x-ray analysis. J Biomed Eng 1982 4(2):107-12.

[22] Qi Y, Lewis G. Influence of assigned material combination in a simulated total cervical disc replacement design on kinematics of a model of the full cervical spine: A finite element analysis study. Biomed Mater Eng 2016 27(6):633-46.

[23] Rieger B. Deutsches Patent und Markenamt DE102017213625A1.

[24] Rieger B. Clinical trial registration no.: PNS Study NCT02936765/ PNR Study NCT02936739.

[25] Rieger B, Jiang H, Reinshagen C, Molcanyi M, Zivcak J, Grönemeyer D, Bosche B, Schackert G, Ruess D. Effects of preoperative simulation on minimally invasive Hybrid Lumbar Interbody Fusion (MIS-HLIF). World Neurosurg. 2017; pii: S1878-8750(17)31092-6.

[26] Rieger B, Jiang H, Polanski W, Molcanyi M, Zivcak J, Reinshagen C, Brautferger U, Mysliwiec P, Schackert G, Welsch N. Is an effective functional replacement of a lumbar segment possible? Biokinemetrie as a surgical projection. MOJ Orthop Rheumatol. 2017; 8(4).

[27] Rieger B, Reinshagen C, Schackert G, Ruess D, Molcanyi M. Biokinemetrie - prospective surgical solutions in degenerative spine. In review since August 2017: Medical Engineering \& Physics.

[28] Rillardon L, Levassor N, Guigui P, Wodecki P, Cardinne L, Templier A, Skalli W. Validation of a tool to measure pelvic and spinal parameters of sagittal balance. Rev Chir Orthop Reparatrice Appar Mot 2003 89(3):218-27.

[29] Rousseau MA, Bradford DS, Bertagnoli R, Hu SS, Lotz JC. DisC arthroplasty design influences intervertebral kinematics and facet forces. Spine J 2006 6(3):258-66.

[30] Schmidt H, Heuer F, Claes L, Wilke HJ. The relation between the instantaneous center of rotation and facet joint forces A finite element analysis. Clin Biomech 2008 23(3):270-8.

[31] Schwab F, Lafage V, Boyce R, Skalli W, Farcy JP.Gravity line analysis in adult volunteers: age-related correlation with spinal parameters, pelvic parameters, and foot position. Spine 2006 31(25):E959-67.

[32] Seligman JV, Gertzbein SD, Tile M, Kapasouri A. Computer analysis of spinal segment motion in degenerative disc disease with and without axial loading. Spine 1984 9(6):56673.

[33] Svedmark P, Berg S, Noz ME, Maguire GQ, Zeleznik MP, Weidenhielm L, Memeth G, Olivecrona H. A new CT method for assessing 3D movements in lumbar facet joints and vertebrae in patients before and after TDR. Biomed Res Int
2015:260703.

[34] Yeager MS, Cook DJ, Cheng BC. Reliability of computerassisted lumbar intervertebral measurements using a noval vertebral motion analysis system. Spine J 2014 14(2):274-81.

\section{Biographical notes}

Bernhard Rieger MD: chief neurosurgeon of the Short-Care Clinic Greifswald, is the co-initiator of the University Comprehensive Spine Center Dresden and founder of i-Pego UG, which deals with innovations and development in the surgical treatment of spinal degeneration.

Clemens Reinshagen MD: previously trained in operative neurosurgery at the University of Cologne, is now working as a postdoctoral research fellow in the Department of Neurosurgery, Brigham and Women's Hospital, Harvard Medical School, Boston.

Dr.h.c. prof. Ing. Jozef Živčák, PhD, is a professor of biomedical engineering at the Technical University in Košice. He was born in 1958. He received his MS and PhD degrees from the Technical University of Košice in 1995. Since 2009 he has been a Doctor Honoris Causa of Uzhorod National University, Ukraine. His research interests include human biomechanics, medical sensors and rehabilitation technology. Today he is head of the Department of Biomedical Engineering and Measurement. Since 1998 he has been an expert witness in machine and electrical technology. He is co-author of more than 280 publications in domestic and foreign journals as well as 9 monographs and 12 books.

Doc. Ing. Radovan Hudák, PhD, was born in 1976 in Košice, Slovakia. He received his MS and PhD degrees in biomedical engineering at the Technical University in Košice in 2000 and 2008. Today Mr. Hudák is an associate professor and head of the prosthetics and orthotics study program and head of the Biomedical Engineering Division at the Department of Biomedical Engineering and Measurement, Technical University of Košice. His research interests include additive manufacturing in medicine, medical thermography, industrial thermography and human biomechanics. Since 2004 he has been the technical assistant at the Centre of Refractive Surgery in Košice. Mr. Hudák has more than 100 publications in domestic and foreign journals. He is co-author of 5 monographs and 10 books.

Prof. Jürgen Hescheler MD: director of the Institute of Neurophysiology at the University of Cologne, is a foremost leading expert in the areas of stem cell research and regenerative medicine, actively maintaining a world-wide scientific cooperation network with eminent pioneers of this field.

Prof. Michael Mokry MD: director of the Clinic of Neurosurgery at the Medical University in Graz, is an internationally renowned neurosurgeon providing the entire scale of high-end operative strategies, furthermore managing a wide range of scientific projects focusing on contemporary translational neurosurgical issues.

Marek Molcanyi MD PhD: is a board-certified neurosurgeon working in Cologne-Bonn area, employed at the Institute of Neurophysiology as leader of a scientific team focusing on stem cell based regenerative therapy, additionally affiliated with the Department of Experimental Neurotraumatology and Clinic of Neurosurgery of the Medical University in Graz. 